\title{
Environmental Impacts of Solid Waste Landfills on Natural Ecosystems of Southern Caspian Sea Coastlines
}

\author{
Seyed Masoud Monavari ${ }^{{ }^{*}}$, Sanaz Tajziehchi ${ }^{1}$, Razieh Rahimi ${ }^{2}$ \\ ${ }^{1}$ Department of Environment, Science and Research Branch, Islamic Azad University, Tehran, Iran; ${ }^{2}$ Department of Natural Re- \\ sources, Islamic Azad University, Arak, Iran. \\ Email: *monavarism@yahoo.com
}

Received April $9^{\text {th }}, 2013$; revised May 12 ${ }^{\text {th }}, 2013$; accepted June $11^{\text {th }}, 2013$

Copyright (C) 2013 Seyed Masoud Monavari et al. This is an open access article distributed under the Creative Commons Attribution License, which permits unrestricted use, distribution, and reproduction in any medium, provided the original work is properly cited. In accordance of the Creative Commons Attribution License all Copyrights (C) 2013 are reserved for SCIRP and the owner of the intellectual property Seyed Masoud Monavari et al. All Copyright (C) 2013 are guarded by law and by SCIRP as a guardian.

\begin{abstract}
The problem of solid waste landfills on Caspian Sea coastlines is one of the current concerns of the Iranian environmental authorities. Physical and environmental constraints as well as shortcomings in present municipal solid waste management are the main factors for environmental pollution and natural resources destruction in this geographical region. In order to reduce the above problems, this study has been carried out on the basis of a comparative assessment of the existing condition of landfill sites in natural ecosystems. In this study, 48 cities of the region have been investigated. All of them are located in Gilan and Mazandaran provinces. Total daily waste production in the study area is about 1209 tons that are dumped in open spaces and/or in aquatic and terrestrial ecosystems. Surveying of 53 physical, adaptability and constraint parameters as well as hygiene and environmental parameters in the landfills, based on "Monavari-94 Method" indicate that the main problem in all of them is a high groundwater table. In $42 \%$ of landfills, the groundwater level is between from 0.5 to 2 meters. This phenomenon may cause severe risks due to the infiltration of leachate into potable groundwater. Indeed, the results of the study show that $87.5 \%$ of the landfills are located in areas with unacceptable conditions. In spite of geographical and environmental problems and constraints and as a final alternative in this respect, the need for sanitary and technical solid waste management is the main need of the study areas.
\end{abstract}

Keywords: Ecosystems; Solid Waste Landfill; Water Pollution; Caspian Sea Coastlines

\section{Introduction}

Solid waste landfills in coastal areas of the Iran are the main current concerns of the authorities in the field of environment protection [1]. Physical and environmental constraints as well as failure of the current system of waste management are the main causes of environmental pollutions and degradation of natural resources in these areas [2].

Critical impacts of indiscriminate solid waste disposal outcomes due to its increasing trend primarily caused by increase of population and change of consumption patterns are one of the most visible causes of ecosocial, hygiene, environmental and sometimes political outcomes in coastline of the Caspian Sea in Northern provinces of Iran [3] (Figure 1).

In this region possessing specific geographical, cli-

${ }^{*}$ Corresponding author. matic, ecological, demographic and economic formations different from other parts of the country, waste disposal management involves special complexities and constraints for which the underlying mechanisms to solve them are still missing [2]. The cheapest and easiest alternative in this area usable for disposal of municipal waste is utilization of dumping method or disposal in open spaces and valuable aquatic and terrestrial ecosystems around the cities or villages which lead to different outcomes in the ecology and water resources of the region. [4].

\section{Materials \& Methods}

\subsection{Study Area}

Gilan and Mazandaran Provinces are located on the southern coast of the Caspian sea. They are one of the most densely populated provinces in Iran, Mazandaran 
Area is $23,842 \mathrm{Km}^{2}$ and population is 2,922,432 and $\mathrm{Gi}-$ lans Area is $14,042 \mathrm{Km}^{2}$ and population is 2,404,861 [5].

\subsection{Methodology}

The methodological principles of this research have been the collection of qualitative and quantitative data and information, observations and samplings, testing and analysis of results based on system approach [6]. In this regard, a questionnaire with 114 questions was prepared to complete the identification criteria form together with field visits to the waste landfill sites [7].

Monavari-95 Method was the method used in this research [8]. (Table 2) In this method, 53 parameters were assessed and analyzed by SPSS software in the following three sections based on collection of library and field information, sampling and testing at waste landfill sites of 48 cities of Gilan and Mazandaran provinces. Index criteria designed for the said method are seen in Table 1. In Table 2, all considered parameters of this method are seen.

a. Physical (20 parameters);

b. Parameters of capabilities and limitations (8 parameters);

c. Environmental-hygiene (25 parameters).

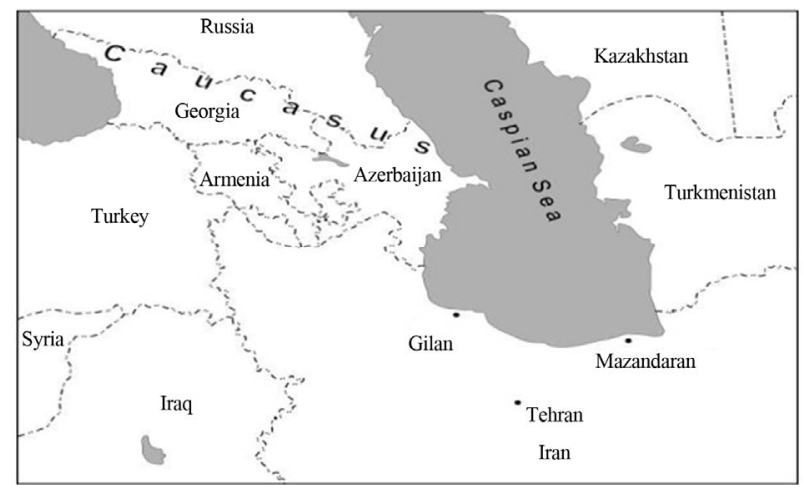

Figure 1. Location of the study area (management and planning organization of Gilan province, 2011).

\section{Results}

A total of 1208.9 tons of solid waste are produced daily in the studied cities [9]. Average daily per capita waste is 906 gr in these areas. Maximum daily solid waste productions 257 tons in Rasht and the minimum amount is $400 \mathrm{~kg}$ in Masouleh which produce $21.3 \%$ and $0.05 \%$ of total solid waste of the region, respectively. The average maximum daily solid waste production per capita of $2 \mathrm{~kg}$ belongs to Chalus and Babol cities and the minimum amount of $107 \mathrm{gr}$ is produced in Abbasabad.

In Chalus, Nowshahr, Rasht, Langerood, Bandar Anzali and Babolsar cities where a total of 5.51\% of the population of the area are living in [10]. 53.2\% of the solid waste of the studied area is produced. In $50 \%$ of the cities, the amount of solid waste production is $\leq 10$ tons, while in $70.8 \%$ of the cities the produced waste does not exceed 20 tons. In these cities, $8.3 \%$ of the collected solid waste is less than 2 tons which should be taken into consideration in planning's of landfill sites.

In all studied cities, the disposal method relies on discharge of solid waste in the environment and use of traditional and unhygienic methods i.e. without processing operation, production of organic fertilizers and recycling [2]. The results of findings based on conditions of landfills and assessment of physical, capabilities and limitations as well as hygienic-environmental parameters are as follows:

\section{a) Physical parameters}

- Distance to city: $63 \%$ of landfills are located at a distance of less than $3 \mathrm{~km}$ from urban services limits, among which $34 \%$ are located at a distance of less than $1 \mathrm{~km}$ and $19 \%$, are within urban limits.

- Distance to village: In $48 \%$ of the studied cases, the distance from the villages to waste landfills is less than $500 \mathrm{~m}$.

- Distance to houses, offices and so on: The distance from the said parameters to waste landfills is less than $500 \mathrm{~km}$ in $51.3 \%$ and $20.5 \%$, respectively.

Table 1. Ranking of index criteria values; Monavari-95 method.

\begin{tabular}{ccccc}
\hline Item & Criteria & Index & Values & Classification \\
\hline 1 & 4 & Excellent & 0 to 12.49 & Acceptable \\
2 & 3 & Good & 12.5 to 24.49 & 25 to 37.49 \\
3 & 2 & Fair & 37.5 to 49.99 \\
4 & 1 & Negligible & 50 to 62.49 & Unacceptable \\
5 & -1 & Weak & 62.5 to 74.49 & 75 to 87.49 \\
6 & -2 & Almost unsuitable & 87.5 to 100 & \\
\hline
\end{tabular}


Table 2. Parameters and criteria; Monavari-95 method (F. Ghanbari, et al., 2011, Monavari, 2005).

\begin{tabular}{|c|c|}
\hline \multirow{20}{*}{ Physical Criteria } & Distance to main road \\
\hline & Status of main road \\
\hline & Status of side road \\
\hline & Soil type in site \\
\hline & Characteristics of suitable soil for coverage \\
\hline & Wind direction \\
\hline & Water table \\
\hline & Transport time \\
\hline & Fault, occurrence of earthquake \\
\hline & Flooding \\
\hline & Distance to city \\
\hline & Distance to village \\
\hline & Distance to houses \\
\hline & Distance to institutes, offices, etc \\
\hline & Distance to river, surface water \\
\hline & Distance to sea \\
\hline & Distance to agricultural lands and gardens \\
\hline & Distance to forest \\
\hline & Distance to recreation centers and resorts \\
\hline & Distance to ecologically sensitive areas \\
\hline \multirow{22}{*}{ Hygienic-Environmental Criteria } & Discharge of industrial waste in site \\
\hline & Discharge of hospital waste in site \\
\hline & Discharge of slaughterhouse waste in site \\
\hline & Discharge of construction waste in site \\
\hline & Discharge of sewage and sludge in site \\
\hline & Groundwater contamination \\
\hline & Seawater contamination \\
\hline & Soil pollution \\
\hline & Landscape pollution and degradation of perspectives \\
\hline & Air pollution \\
\hline & Production of unpleasant odor \\
\hline & Records of contamination and damage \\
\hline & Destruction of wildlife habitats \\
\hline & Degradation of recreational areas and resorts \\
\hline & Destruction of flora \\
\hline & Mortality of animals \\
\hline & Indirect pollution and destruction \\
\hline & fencing of light objects \\
\hline & Visual barriers \\
\hline & Stockade of the area \\
\hline & Decline in real estate economical values \\
\hline & The planting of greenery \\
\hline \multirow{8}{*}{ Capabilities \& Limitations } & Potential of future application \\
\hline & Facilities of development \\
\hline & Rehabilitation, reconstruction and improvement needs \\
\hline & Sufficient space in the future \\
\hline & Existence of proper disposal sites in the area \\
\hline & Complaints and protests from local people \\
\hline & Costs of management system \\
\hline & Equipment and facilities in the site \\
\hline
\end{tabular}


- Distance to river and sea: In $35 \%$ of the sites, the waste directly discharges into river, and the distance from $4.62 \%$ of them to these resources is less than $100 \mathrm{~m}$. In accordance with the analysis of findings, distances from the sites to river and sea are less than 1 $\mathrm{km}$ in $4.81 \%$ and $5.27 \%$ of them, respectively.

- Distance to agricultural lands and gardens, forest, recreation areas and ecologically sensitive areas: Discharges of the waste in the said areas are $3.6 \%, 27 \%$, $3.6 \%$ and $15 \%$, respectively.

- Distance to main road and status of main and side roads: Transit routes of the vehicles carrying the waste have high traffic in $42 \%$ of cities and are located out of urban limits. In $20 \%$ of the cases, distance from main roads to landfills is less than $50 \mathrm{~m}$ and in $33 \%$ of them, the distance was less than $150 \mathrm{~m}$ and between $150 \mathrm{~m}$ and $1 \mathrm{~km}$. With respect to status of side roads, the transit route in $78 \%$ of them has some problems such as rugged, dirt and steep roads, and in $25 \%$ of sites the traffic is confronted with unanticipated events such as flooding, settlement of the road, etc.

- Soil type and suitability of soil to cover the solid waste: Considering the fact that soil formations in most of landfills are similar, due to different locations of the sites, in $72 \%$ of them the existing soil type is gravel, pebbles and debris. There are clay soils in $50 \%$ of the sites; in $23 \%$ of landfills the suitability of these soils to cover the waste is low and if they are used, it will lead to medium destruction of the site. In $40 \%$ of the sites, in case of using the soil, the destruction will be medium to high.

- Wind direction: Due to occurrence of hygienic-environmental outcomes, identification of wind direction in landfills is of special importance. In $27 \%$ of sites, strong wind blows toward residential centers. In $72 \%$ of the sites, a major problem is caused by the wind blowing towards the road and residential centers.

- Water table: Discharge of waste in the studied area is highly problematic due to the high water table. According to the results, water table is less than $10 \mathrm{~m}$ in $89 \%$ of the sites, and in $42 \%$ of them it is between 0.5 to $2 \mathrm{~m}$.

- Transport time: One of the advantages of landfill sites is the low transport time of waste from the city to landfill site. In $5.14 \%$ of cities, the transport time of wastes has been calculated more than $60 \mathrm{~min}$ and in $50 \%$ of them, it is between 35 to $40 \mathrm{~min}$.

- Fault, occurrence of earthquake and flooding: Environmental hazards such as faults and or flooding of waste landfill sites are of limiting factors [11]. In 31\% of the sites, the fault with a history of severe earthquake has been reported so that $52.5 \%$ of them have less than $10 \mathrm{~km}$ with different earthquake records.
$28 \%$ of the sites are located in flooding areas with a distance of less than $500 \mathrm{~m}$, but $23 \%$ of them are in areas without flooding with a distance of 1 to $5 \mathrm{~km}$.

\section{b) Capabilities \& Limitations}

- Future applications: Landfill sites in the study area are suitable for future applications after completion of site capacity. In $27 \%$ of them, the application is possible with a high cost. In $13 \%$ of them, the excellent condition is possible with the least cost and most wide application.

- Development, improvement and rehabilitation: In $60 \%$ of sites, the development condition has been estimated weak to feasible and in $27 \%$ of them there is no possibility of development. In $50 \%$ of them moderate to high need for rehabilitation may be met with a high cost. In $21 \%$ of landfill sites, a high need for improvement and rehabilitation has been felt which is very costly.

- Sufficient space for future: Studies show that $25 \%$ of the landfill sites have a capacity of less than 1 year for discharge of solid wastes and $23 \%$ of them have been already completed.

- Existence of landfill sites in the region: In $17 \%$ of the studied areas, there are no suitable lands for landfill site selection. In $29 \%$ of them, although new landfill sites may be proposed, despite being low cost, are inappropriate.

- Complaints and protests from local people: One of the current problems of landfill sites in the study area is the complaints and protests of the local people. In $52 \%$ of these sites, formal protests and complaints have been made by more than one person from nearby residents, and in $33 \%$ of them constant protests and complaints have been made by more than 10 people.

- Costs of management: Although the distances from current landfill sites to production and collection centers are low, landfill costs in $33 \%$ of sites have been reported from moderate to high. In $19 \%$ of them the costs are too high, and in $23 \%$ of them the costs are appropriate and reasonable.

- Existing of equipment and installations in landfill sites: Deployment and application method of different equipment for landfill are considered one of the basic principles of management of landfill sites [12]. Nevertheless, $33 \%$ of these sites lack this equipment, and in $58.64 \%$ of the sites this equipment is incomplete and insufficient which is used on a case-by-case basis as well as monthly or weekly (once in a week) and under the semi-permanent conditions.

\section{c) Hygienic \& Environmental}

- Discharge of industrial, hospital, slaughterhouse, sewage and sludge waste:

Considering the waste generated in urban areas, large 
quantities of this material require disposal [13]. Except for a small number of landfill sites of big cities such as Rasht, Babolsar and Chalus, in other sites household waste is the major one due to low production of the other wastes. Hence it is observed that in $48 \%$ of the landfill sites industrial waste are not generally discharged. Discharges of hospital, slaughterhouse, construction and sewage waste have been reported $44 \%, 42 \%, 23 \%$ and $71 \%$, respectively. In $23 \%$ of the sites, industrial waste discharge rate varies by more than 70 to 200 kilograms and in $50 \%$ of them over $200 \mathrm{~kg}$ of wastes are daily discharged due to growth of construction and lack of suitable sites for the disposal of dirt and debris. In $71 \%$ of landfill sites sewage and sludge waste are not discharged, but in $19 \%$ of them, between 70 to 200 cubic meters of sludge and wastewater are discharged daily.

- Surface waters pollution, groundwater and seawater contamination: The analysis in the field of water pollution caused by waste discharge in landfill sites shows that in $27 \%$ of sites surface water pollution is very unsuitable and permanent and in $45.3 \%$ of the sites, it is moderate and very high. Contamination of ground water in $67.3 \%$ of landfill sites is also moderate and very unsuitable and in $29 \%$ of them this condition is unsuitable and permanent. Due to long distance from landfill sites to the sea, in $81 \%$ of sites seawater contamination has not occurred but due to waste discharge that occurs in the vicinity of some landfills, surface contamination has been observed in $84 \%$ of them.

- Soil pollution: Surface soil contamination due to the release and disposal of solid waste on land at $4.31 \%$ of the sites is moderate to very unsuitable and permanent, and in $27 \%$ of them it is low and casual.

- Landscape pollution: Landscape pollution in $78 \%$ of cases is moderate to unsuitable which leads to reduction of different values of the environment.

- Air pollution and production of unpleasant smell: Air pollution and production of unpleasant smell caused by burning of solid waste by residents or street cleaners, self-incineration or decomposition of organic waste in $6.42 \%$ and $80 \%$ of the sites are observed at moderate to very unsuitable and permanent status, respectively. Air pollution in $23 \%$ of the sites is significant and undesirable odor emissions in $23 \%$ of these sites are very unsuitable and permanent.

- Destruction of habitats: Considering the value of habitats in the study area, operations of landfills and the activities carried out there have led to destruction of valuable habitats in $75 \%$ of the sites under moderate to very unsuitable conditions. In $31 \%$ of the landfills, the destruction of habitats is in high to very unsuitable status.
- Destruction of flora: The flora of the study area which is considered one of the most valuable places for plants growing in the country has not been protected against harm of the activities performed in landfill sites, and in $21 \%$ of the sites formed of valuable species of plants the destruction is too high in $3.63 \%$ of them the status of destruction is moderate to very unsuitable and for all species distractive effects have been observed.

- Degradation of recreational areas and resorts: $58 \%$ of landfills have not caused the degradation of recreational areas and resorts; however in areas with moderate to high value, moderate to very unsuitable degradation has occurred in 26.35 of the landfills.

- Indirect pollution and destruction: In $40 \%$ of places this situation is very unsuitable and in $90 \%$ of them the situation has been recorded as casual, unsuitable to very unsuitable.

- Mortality of animals: Considering the destruction of animal habitats as well as rate of emission of pollution and degradation, mortality of animals occurs due to lack of suitable conditions for aquatic and terrestrial animal species [14]. In $2.52 \%$ of the existing landfills of study area, occurrence of animals' mortality is moderate and casual to very unsuitable and permanent. In $29 \%$ of them this situation is moderate and casual.

- Records of contamination and damages: Pollutants and destructive factors in the study area have caused that $23 \%$ of the sites have high records of damages as well as pollution with high intensity. In $2.54 \%$ of them the pollution damages is weak to unsuitable and its record is moderate to unsuitable.

- Scattering of litters and soil cover: Scattering of light objects such as paper and plastic due to the wind blowing in the site or transport of waste with vehicles is one of the most common aspects of failure of management system. In $84.1 \%$ of the landfill sites scattering of light objects is seen permanently and around the sites. In $40 \%$ of landfills this situation is permanent but it only happens in around of the sites. One of the causes of these outcomes is the lack of soil cover which in $3.80 \%$ of the sites it is weak and casual and in $38 \%$ of the sites it is not used.

- Visual barriers and green space: Lack of visual barriers in $6.46 \%$ of the sites caused that landfill sites can be seen from distances more than $500 \mathrm{~m}$. In $25 \%$ of all sites, these barriers which are manmade or natural are in excellent conditions and include green space, fencing or natural factors such as hills or topography which cause the landfill to remain hidden from the view of passersby. Green space constructed for different purposes such as fences, observation of environmental principles in landfills has weak status in 
$70.6 \%$ of sites. Hence it is clear that this important factor has not been considered, in so far as in $35 \%$ of the sites green space has not been constructed at all and in many of them degradation has been done with different intensities due to lack of management and neglect of local people.

- Fencing and the animals: One of the important issues in the landfills that have been overlooked in terms of management approach is the lack of fencing in various forms [15]. Based on the performed observations, $75 \%$ of sites lack fences and doors and in the rest of them this method has some shortcomings and defects and the concept of this method is not acceptable [16]. Hence this failure has resulted in a situation that in $33 \%$ of the landfills, there are domesticated animals in large numbers and in $87 \%$ of them there are wild and domesticated animals permanently and in large numbers.

- Decline in real estate values: All of defects and failures in landfill sites have caused that from the economic point of view, the prices of lands and buildings in the vicinity of the sites decline. In $29 \%$ of the sites, this case has been associated with very high depreciation and included buildings and trading. In $56.2 \%$ of the areas this situation is in the moderate to very unsuitable status.

\section{Conclusions}

Considering the increasing production of municipal solid waste and population increase in the south coasts strip of the Caspian Sea in Gilan and Mazandaran provinces, destructive effects and contamination emissions of waste landfill sites have caused the loss and reduction of carrying capacity of aquatic and terrestrial ecosystems of the region due to lack of efficient solid waste management.

The results of this research show that because of the wide range of aquatic ecosystems, they are more vulnerable to pollution and increasing degradation. Because of easy access and availability of communication ways as well as since the rivers cross the cities, in many towns and villages solid wastes directly discharge into water sources such as rivers, ponds and seashores. In 35\% of the study area, the solid waste directly discharge into river and in the $64 \%$ of them the distance to this water resource is less than $100 \mathrm{~m}$.

Since the groundwater in $42 \%$ of landfills is between 0.5 to $2 \mathrm{~m}$, the possibility of groundwater contamination is very high and in unsuitable conditions. Since the discharged wastes generally contain industrial and healthcare waste, and there are toxic and pathogenic elements in household waste, these sources are contaminated very soon. Aqua ecosystems of the area such as Anzaliwetl and have habitat value for variety of fish and birds as well as drinking and irrigation values and recreational importance. It is essential to take immediate actions to prevent the process of degradation and contamination.

\section{Recommendations}

According to the results of this study, the following cases are recommended:

1) Lack of site selection criteria and regulations, operation and maintenance instructions after closing of landfills in coastal areas of the Caspian Sea which should be placed in the context of environmental regulations is the most important problem in the field of solid waste landfill. It is recommended that Iran Department of Environment to take measures to develop criteria, regulations and specific standards for these areas. It is required that the above cases to be approved by the Supreme Council for the Environmental Protection and to be binding in the form of regulations approved by Islamic Parliament of Iran.

2) Department of the Environment (DoE) offices in the study areas are legal supervisors for landfill operations in provinces. Issuance of permit for construction, operation and closing of landfills and monitoring of all activities carried out in these sites shall be done by these offices.

3) Due to the environmental problems in some landfills in coastal areas of the Caspian Sea, it is required to take immediate actions to close the polluting landfills by the municipalities especially those located in natural ecosystems.

4) In the present situation, there are economic-social and environmental limitations for selection of new sites due to lack of appropriate lands for landfills. To reduce the said bottlenecks, it is recommended that with respect to some cases such as costs of transportation, amount of solid waste produced, manpower, number of special vehicles for transportation, financial resources and other basic needs, all towns of a conurbation use a qualified landfill with sufficient and appropriate capacity for acceptance of waste based on this study. This management method will result in reduction of adverse environmental impacts in the area and will also lead to equilibrium of the local economy.

5) To reduce the hygiene and environmental problems of the current landfills with sufficient capacities for future years and negligible contamination burden, it is necessary to apply engineering measures for landfills such as soil lining and compaction in order to comply with the regulations.

6) According to the results of this study, the most optimized method to solve the problems of landfills in the study area is to implement the operation of recycling programs and compost production. If the said strategies are observed in management programs of solid waste in the area, and with respect to the need for landfills, application of engineering methods such as trenches, lining 
soil and compaction of waste is necessary.

7) In terms of future strategies of optimization and development of the solid waste management system, existence of landfills for the waste produced by implementation of recycling and compost production operations will be necessary. Considering the fact that under such conditions the amounts of buried waste material will be significantly reduced, it is recommended that with respect to economic considerations, the central landfills to be used to accept the waste of nearby towns.

8) It is required to transfer the toxic and hazardous waste produced by industrial factories and workshops to specific areas under supervision of DoE offices. In this regard it is recommended to take measure to select and design landfills for industrial and non-industrial toxic and hazardous waste. Constitution of a scientific and executive committee to solve the above problem is a dire need which should be a priority in waste management of the study area.

9) To reduce the contamination of the landfills, legal prohibition of sanitary waste discharge in these landfills is essential. Separate collection of the above waste and transfer to a central incinerator which is administered in different regions of the study area based on the amount of waste production and the suitable capacity will be the most important method to observe hygiene and environmental considerations.

10) Considering the economic and environmental benefits, recycling, reduction and separation of at source in urban and rural areas should be encouraged. Much of the cost of landfill operations will be reduced through provision of various incentives at the community level, education of the people from all walks of life as well as application of principle methods to absorb and recruit public and government cooperation and participation. Furthermore, the conditions to generate revenue create jobs as well as promote the technical level of operations in landfills through revenues from change and selling of the materials will be prepared.

11) Considering the ratification of waste bill, it is necessary to apply its provisions to reduce environmental outcomes of waste in the study area. In this case, it is necessary to pay special attention to improve the culture of indigenous communities and their education particularly at management levels. Implementation of separation at source programs and feasible optimized changes in consumption patterns in the region will be also effective in reduction of the environmental burden of waste disposal.

12) Composting plants have higher priority than the landfills due to economic reasons such as creation of income, jobs as well as containing hygiene and environmental benefits. It is suggested that along with the recycling in source programs, and considering the amount of waste production in different conurbations, establishment of composting plants must be on priority development projects of the area.

13) Establishment of a coherent and efficient organizational unit of solid waste management in accordance with standards of the study area is essential for designing, planning, management, supervision and research. This unit can be strengthened through cooperation and coordination with university centers, offices of DoE, Environmental Health, Natural Resources and other related institutions and organizations.

\section{REFERENCES}

[1] O. Abessi and M. Saerdi, "Hazardous Waste LandfillSitting Using GIS Technique and Analytical Hierarchy Process," Environment Asian, Vol. 3, No. 2, 2010, pp. 43-60.

[2] A. Al-Jarrah and H. Abu-Qdnis, "Municipal Solis Waste Landfill Siting Intelligent System," Waste Management, Vol. 26, No. 3, 2006, pp. 229-306.

[3] I. Anzi, B. Inanc, M. N. Hassan, "Overview of Waste Disposal and Landfills/Damps in Asian Countries," Journal of Material Cycles and Waste Management, Vol. 6, No. 2, 2004, pp. 104-110.

[4] J. M. Bali, "Aspects of Landfill Site Selection," Proceeding of the Institute of Waste Management, Mitra, Tehran, 2004.

[5] S. M. Monavari, "Environment of Gilan," Gilan Book, Tehran, 1995.

[6] S. M. Monavari, "Fundamental Considerations in the Planning and Environmental Management of Waste Landfill sites," Publications of Office of Human Environment of DoE, Tehran, 1986.

[7] S. Purdy and F. Sabugal, "Site Selection Study for a New Sanitary Landfill for the Subic City Metropolitan Authority, Olongapo, Philippines," Proceeding of Sardina, International Waste Management and Landfill Symposium, CISA, Cagliari, 2001.

[8] N. B. Chnge, G. Parrathinathan and J. B. Breeden, "Sitting GIS with Fuzzy Multicriteria Decision-Making for Landfill Sitting in a Fasr Growing Urban Region," Journal of Environmental Management, Vol. 12, 2007, pp. 70-120.

[9] Environmental Studies Institute, "Solid Waste Management in Gilan and Mazandaran Province," Gilan DoE, Rasht, 1993.

[10] Environmental Studies Institute, "Solid Waste States in North of Iran," Environmental Studies Institute, Tehran, 1986.

[11] A. Gemitzi, V. A. Tsithrintzis, E. Voudrias, C. Petales and G. Stravodimos, "Combining Geographic Information System, Multi Criteria Evaluation Techniques and Fuzzy Logic in Sitting MSW Landfill," Environmental Geology, Vol. 51, No. 6, 2007, pp. 14-17.

[12] A. Goodarzi, "Strategic Design of Solid Waste Manage- 
ment for Rasht City," MSc Thesis, Payam Noor University of Tehran, Tehran, 2010.

[13] Management and Planning Organization of Gilan Province, "Economic and Social Development Plan of Gilan Province," Management and Planning Organization of Gilan Province, Rasht, 2011.

[14] S. M. Monavari, "Environmental Impact Assessment," Department of Environment IR, Islamic republic of Iran, Iran, 2005.
[15] F. Ghanbari, F. A. Sharee, S. M. Monavari and N. Zaredar, "A New Method for Environmental Site Assessment of Urban Solid Waste Landfills," Environmental Monitoring and Assessment, Vol. 184, No. 3, 2012, pp. 12211230.

[16] Management and Planning Organization of Mazandaran Province, "Economic and Social Development Plan of Mazandaran Province," Management and Planning Organization of Mazandaran Province, Sari, 2011. 